\title{
Health-related quality of life in children and adolescents with end-stage renal disease receiving dialysis in Johannesburg
}

\author{
P N Obiagwu, ${ }^{1,2}$ MBBS, FWACP (Paed); B Sangweni, ${ }^{2}$ RN, MSc; G Moonsamy, ${ }^{2}$ MB ChB, FCPaed (SA); \\ T Khumalo, ${ }^{2} \mathrm{MB} \mathrm{ChB}, \mathrm{FCPaed}(\mathrm{SA}) ;$ C Levy, ${ }^{2} \mathrm{MB} \mathrm{ChB}$, FCPaed (SA)

\begin{abstract}
${ }^{1}$ Paediatric Nephrology Unit, Department of Paediatrics, Aminu Kano Teaching Hospital and Bayero University, Kano, Nigeria ${ }^{2}$ Division of Paediatric Nephrology, Department of Paediatrics and Child Health, Charlotte Maxeke Johannesburg Academic Hospital and the University of Witwatersrand, Johannesburg, South Africa
\end{abstract}

Corresponding author: P N Obiagwu (patience.obiagwu@gmail.com)

\begin{abstract}
Background. Limitations in daily activities can have a major impact on the quality of life in children and adolescents. Long-term dialysis tends to restrict children from carrying out similar activities to those of their peers.

Objective. To analyse the health-related quality of life of children and adolescents with end-stage renal disease on dialysis in Johannesburg. Methods. A hospital-based, cross-sectional study which assessed the health-related quality of life (HRQOL) of patients undergoing haemodialysis (HD), automated peritoneal dialysis (APD) and continuous ambulatory peritoneal dialysis (CAPD) using the Pediatric Quality of Life Inventory (PedsQL 3.0) and end-stage renal disease (ESRD) module as the instrument. The instrument is a questionnaire comprising 7 domains with a total of 34 questions/items. Child reports as well as parent proxy reports were obtained. Questionnaires were administered to all patients and parents/caregivers of children on all forms of chronic dialysis.

Results. Twenty-seven children and adolescents were studied. The mean (standard deviation (SD)) age of the study participants was 14.4 (4.8) years (range 5 - 25). Fourteen patients were on HD while 13 were on peritoneal dialysis (8 on APD and 5 on CAPD). Those on HD were significantly older, with a mean (SD) age of 16.6 (3.2) years, compared with the mean (SD) age of those on PD, which was 12.1 (5.3) years $(p=0.007)$. Moreover, those on HD had been on dialysis for a longer period of time, with a mean (SD) period of 4.5 (3.3) years, compared with those on PD who had been on dialysis for a mean (SD) duration of 1.7 (0.8) years ( $p=0.006)$. The HRQOL was lower in most domains in the HD group compared with the PD group. Among the patients on PD, the HRQOL scores were lower in the APD group compared with the CAPD group $(p>0.05)$. The ratings by the parent proxies were higher than those reported by the children themselves in most domains. When compared with the population mean HRQOL scores derived from a healthy paediatric population, the mean HRQOL scores of the children with ESRD on dialysis were significantly lower for both child $(t=-11.1 ; p=0.001)$ and parent proxy reports $(t=-7.2 ; p=0.001)$.

Conclusion. HRQOL is low in children with ESRD receiving chronic dialysis. It tends to be much lower in children on HD when compared with those on PD. PD appears to be more acceptable to children and parents/caregivers than HD.
\end{abstract}

S Afr J Child Health 2018;12(2):58-62. DOI:10.7196/SAJCH.2018.v12i2.1457

Chronic kidney disease (CKD) is a significant public health problem, particularly in sub-Saharan Africa where resources for management are limited. End-stage renal disease (ESRD), which is the extreme stage in the spectrum of $\mathrm{CKD}$, implies that the patient requires some form of renal replacement therapy (RRT) which could be haemodialysis (HD), peritoneal dialysis (PD) or renal transplantation.

The care of a child with ESRD is fraught with challenges for the parent, the caregiver as well as the healthcare system. The child is burdened with physical, social, emotional and psychological issues, and these affect the child's quality of life. ${ }^{[1-3]}$ The subjective perception of how health-related factors affect well-being and life satisfaction is known as the health-related quality of life (HRQOL) ${ }^{[4]}$

The importance of the assessment of the HRQOL in children with ESRD cannot be overemphasised as technological advances have made it possible to extend their duration of survival. They can therefore reach adulthood but find themselves facing several other challenges, specifically financial challenges. Moreover, as they grow to become young adults, children with ESRD are faced with challenges of independent living such as securing gainful employment and maintaining relationships. Optimal care of the paediatric patient with ESRD should therefore include an assessment of their HRQOL to better understand these challenges and to keep these in focus such that holistic care may be administered.
HRQOL is usually assessed using various instruments such as the Kinder Lebensqualitat Fragebogen (KINDL) questionnaire, ${ }^{[5]}$ the Kidney Disease Quality of Life - Short Form (KDQOL-SF) ${ }^{[6]}$ and the Paediatric Inventory of Quality of Life Core Scales (PedsQL version 4.0). ${ }^{[7]}$ These instruments have been validated for use in healthy and sick children. The PedsQL Version 4.0 has been validated for use in children with a wide variety of chronic illnesses including ESRD. ${ }^{[8,9]}$

Numerous studies on HRQOL in children with ESRD have been conducted in developed countries. ${ }^{[7,9-17]}$ The reported results have varied, with some studies reporting better HRQOL in PD patients compared with HD patients, ${ }^{[7,15,16]}$ while others report no differences between patients on either modality ${ }^{[9,12,14]}$ A uniform finding of several of these studies, however, is that children with chronic conditions such as ESRD have lower HRQOL scores when compared with healthy children. ${ }^{[7-9,12,14-17]}$ There are no studies on the HRQOL of children with CKD in sub-Saharan Africa. Unfortunately, the region is fraught with several socioeconomic, health and psychologic challenges which affect healthcare quality, affordability, availability and delivery, and these could affect the health-related quality of life of the children. Furthermore, sociocultural characteristics of the region might not afford the children opportunities to express 
their concerns and challenges fully as they relate to their health conditions and specific needs.

\section{Objective}

The aim of the study was to analyse the HRQOL of children and adolescents with ESRD on dialysis in Johannesburg, and compare their reports with those given by their caregivers. We hypothesised that children receiving dialysis would have lower HRQOL scores than healthy counterparts, that children on APD would have higher HRQOL scores than those on HD or CAPD, and that the parents or proxies would report higher HRQOL scores when compared with those reported by the children.

\section{Methods}

This was a cross-sectional study carried out on children and adolescents receiving either chronic $\mathrm{HD}$ or chronic $\mathrm{PD}$ at the nephrology unit of Charlotte Maxeke Johannesburg Academic Hospital (CMJAH). CMJAH is a tertiary referral centre which provides specialist care to all persons from the referral regions of the province and neighbouring provinces. Each participant in this study had his/her HRQOL assessed. Patients were eligible if they were on a form of chronic dialysis. Children who had been hospitalised within the preceding two weeks, and those who had received a kidney transplant were excluded. All children and adolescents receiving chronic dialysis at the hospital, as well as their caregivers, participated in the study.

\section{Participants}

Baseline sociodemographic and clinical details were obtained from the participants, as well as from a folder review. These included age, gender, baseline diagnosis, mode of dialysis, date of commencement and duration on dialysis, number of medications, number of routine clinic visits, number of hospital visits for dialysis and dialysis-related complaints and number of hospitalisations within the previous 6 months, attendance at hospital school as well as any significant nonrenal comorbidities diagnosed in the patient. The hospital school is a school established within the hospital for children with chronic conditions such as ESRD to attend because of the long hours they spend at the hospital for procedures such as dialysis. Having a school on the hospital premises allows the children to receive as much holistic care as possible while they receive treatment for their medical conditions.

\section{Assessment of HRQOL}

We assessed the HRQOL of patients undergoing HD, automated peritoneal dialysis (APD) and continuous ambulatory peritoneal dialysis (CAPD) using the Pediatric Quality of Life Inventory (PedsQL) End Stage Renal Disease module version 3.0 as the instrument. We received the user agreement from Mapi Research Trust in Lyon, France. The instrument is a questionnaire comprising 7 domains with a total of 34 questions/items. The domains include: general fatigue (4 items), about my kidney disease (5 items), treatment problems (4 items), family and peer interactions (3 items), worry (10 items), perceived physical appearance (3 items) and communication (5 items). The PedsQL ESRD module 3.0 is available in 5 age-specific report versions: toddler $(2-4$ years, only by caregiver proxy report), young child (5- 7 years), child ( $8-12$ years), teen (13 - 18 years) and young adult (18 - 25 years). Child reports as well as parent proxy reports were obtained. Questionnaires were administered to all patients and parents/caregivers of children on all forms of chronic dialysis. Children and caregivers had the questionnaires administered to them in the language they felt most comfortable with and an interpreter was used in cases of language barriers. The questionnaires were orally administered to the children during HD sessions, PD or HD clinic visits, or completed at home and returned to the primary investigator. A Likert response scale (reverse scoring with linear transformation) was used in assigning scores, with higher scores indicating better HRQOL.

\section{Ethical considerations}

Each participant was given an information sheet which explained in detail what was involved in the study. Signed informed consent was obtained from either a parent/legal guardian or child older than 8 years while verbal assent was obtained from the younger children. The study was approved by the Human Research Ethics Committee of the University and the Clinical Directorate of the hospital (ref. no. M141133).

\section{Data analysis}

Data were entered into a spreadsheet and analysed using the SPSS statistical software package version 20.0 (IBM Corp., USA). Baseline characteristics were summarised as continuous data and presented as mean (SD). Discrete variables were summarised as counts and percentages. Differences in continuous data were analysed with Student's $t$-test while those for categorical data were analysed using the $\chi^{2}$ test. The primary outcome of interest was the disease-specific quality of life score. Secondary outcomes included scores for the 7 domains of the PedsQL ESRD module 3.0. The independent variables were patients' characteristics as determined from baseline patient data obtained from the folder review. Mean HRQOL scores were calculated for each domain for the APD, CAPD and HD sample groups, and differences were compared using the independent samples $t$-test or analysis of variance (ANOVA). A univariate analysis was performed to find which variables were associated with HRQOL scores of both HD and PD patients. A $p$-value of $<0.05$ was considered to be statistically significant in all analyses.

\section{Results}

Twenty-seven children and adolescents and their basic characteristics were studied (Table 1). There were 14 male and 13 female subjects $(\mathrm{M}: \mathrm{F}=1.08: 1)$. The mean $(\mathrm{SD})$ age was $14.4(4.8)$ years (range $5-25$ ) years. Fourteen patients were on in-centre HD while 13 were on PD ( 8 on APD and 5 on CAPD). Those who were on HD were significantly older, with a mean (SD) age of 16.6 (3.2) v. $12.1(5.3)$ years $(p=0.013)$, and had been on dialysis much longer, for a mean (SD) duration of 4.5 (3.3) v. $1.7(0.9)$ years $(p=0.006)$, than those who were on PD. There was no significant difference in the mean number of medications, hospitalisations and routine clinic visits in the preceding 6 months among the children on the three modes of dialysis. However, the patients receiving HD had a significantly higher number of hospital visits for dialysis and dialysis-related complaints than those who were on PD. Half of the children on HD attended the hospital school.

There was a wide range of underlying diagnoses of the aetiology of ESRD in the patients (Table 2). Eleven children (40.7\%) had significant non-renal comorbidities. Of these, 5 children were on APD and 6 were on HD. The comorbidities comprised HIV infection in 5 children, dilated cardiomyopathy in 4 , spina bifida in 2, 1 case of mitochondrial myopathy and 1 severe hearing impairment. Two children, one on HD and one on APD, had a combination of HIV infection and dilated cardiomyopathy. The mean (SD) HRQOL scores were lower in children who had the presence of a significant non-renal comorbidity - 59.7 (13.3), compared with those who did not have significant non-renal comorbidity - 55.3 (10.4), but this was not of statistical significance $(F=0.829, p=0.371)$. There was also no association between the presence and number of significant non-renal comorbidities with mode of dialysis $(d f=2 ; F=0.833 ; p=0.447)$. 
Table 1. Basic characteristics of participants with ESRD $(N=27)$

\begin{tabular}{|c|c|c|c|c|c|}
\hline Parameter & $\begin{array}{l}\text { Total } \\
(N=27)\end{array}$ & $\begin{array}{l}\text { HD } \\
(n=14)\end{array}$ & $\begin{array}{l}\mathrm{APD} \\
(n=8)\end{array}$ & $\begin{array}{l}\text { CAPD } \\
(n=5)\end{array}$ & $p$-value \\
\hline Age (years), mean (SD) & $14.4(4.8)$ & $16.6(3.2)$ & $12.2(3.7)$ & $11.8(7.8)$ & 0.047 \\
\hline \multicolumn{6}{|l|}{ Gender } \\
\hline Male & 14 & 11 & 2 & 1 & \\
\hline Female & 13 & 3 & 6 & 4 & \\
\hline Hours on dialysis, mean (SD) & $3.1(2.8)$ & $4.5(3.3)$ & $1.6(0.5)$ & $1.9(1.3)$ & 0.024 \\
\hline Number of medications, mean (SD) & $10.1(3.0)$ & $9.5(2.6)$ & $11.7(3.8)$ & $9.4(1.5)$ & 0.198 \\
\hline Number of routine clinic visits in past 6 months, mean (SD) & $5.2(1.4)$ & $5.0(1.6)$ & $5.7(1.0)$ & $5.0(1.2)$ & 0.461 \\
\hline $\begin{array}{l}\text { Number of hospital visits for dialysis and dialysis-related } \\
\text { complaints, mean (SD) }\end{array}$ & $40.0(32.8)$ & $71.0(1.6)$ & $6.6(0.9)$ & $6.6(1.1)$ & 0.000 \\
\hline Number of hospitalisations in past 6 months, mean (SD) & $1.1(1.4)$ & $1.2(1.4)$ & $0.9(1.4)$ & $1.2(1.6)$ & 0.860 \\
\hline Attends hospital school, $n(\%)$ & & $7(50)$ & $0(0)$ & $1(20)$ & 0.039 \\
\hline
\end{tabular}

Table 2. Underlying diagnoses in children with ESRD

\begin{tabular}{ll}
\hline Underlying aetiology of ESRD & $\boldsymbol{n}(\%)$ \\
\hline Focal segmental glomerulosclerosis & $6(22.2)$ \\
Posterior urethral valves & $3(11.1)$ \\
HIV immune complex kidney disease & $2(7.4)$ \\
Neuropathic bladder & $2(7.4)$ \\
Congenital nephrotic syndrome & $2(7.4)$ \\
Cystinosis & $2(7.4)$ \\
Membranoproliferative glomerulonephritis & $2(7.4)$ \\
Cystic kidneys & $1(3.7)$ \\
Haemolytic uraemic syndrome & $1(3.7)$ \\
Crescentic glomerulonephritis & $1(3.7)$ \\
HIV-associated nephropathy & $1(3.7)$ \\
Immunoglobulin A nephropathy & $1(3.7)$ \\
Haemolytic uraemic syndrome with secondary global & $1(3.7)$ \\
sclerosis & \\
Immune-mediated glomerulonephritis & $1(3.7)$ \\
Unknown & $1(3.7)$
\end{tabular}

$\mathrm{ESRD}=$ end-stage renal disease

\section{HRQOL scores}

The mean (SD) HRQOL scores for the study population was 57.9 (12.2) for the children and 60.5 (15.4) for the parent proxies. The mean (SD) HRQOL scores for both male and female genders were 53.8 (11.2) and 62.4 (11.9), respectively $(t=1.928 ; p=0.066$ in the study population). Females reported higher mean HRQOL scores in all domains except the ESRD Worry domain. However, this was not of statistical significance ( $p>0.05$ in all domains).

The mean (SD) HRQOL score for children on HD was 54.7 (9.7) while it was 57.8 (15.3) and 67.1 (10.4) for those on APD and CAPD respectively $(F=2.049 ; p=0.151)$. The mean (SD) HRQOL scores for children and parent proxies in the various domains were studied and the HRQOL was lower in most domains in the HD group compared with the PD group as a whole. However, none reached statistical significance except in the ESRD General Fatigue domain (Table 3).

The mean differences in HRQOL scores between parent proxies and the children with ESRD were compared (Table 4). The parent proxies reported mean HRQOL scores which were mostly higher than those reported by the children themselves in all domains except the General Fatigue domain and the About My Kidney Disease domain. However, the mean difference was only significant in the Communication domain $(t=2.312 ; p=0.030)$.
Although the children who were on HD had spent a significantly longer time on therapy than had those on PD, there was no significant effect of duration on dialysis on HRQOL scores when comparing children who had spent $1(F=2.272 ; p=0.144), 2(F=0.242 ; p=0.627)$, $3(F=0.237 ; p=0.631)$ or 4 years $(F=0.229 ; p=0.637)$ on dialysis.

Among the patients who were on $\mathrm{PD}$, the HRQOL scores were lower in most domains in the APD group when compared with the CAPD group. This was, however, only significant in the domain of General Fatigue in which the children who had CAPD reported statistically significantly higher HRQOL scores than those who had APD ( $p=0.032$ ). This significance was not found on comparison of other domains or among the parent proxies.

When compared with the population sample mean HRQOL scores of a healthy paediatric population, ${ }^{[17]}$ the mean HRQOL scores of the children with ESRD on dialysis were significantly lower for both child and parent proxy reports ( $p<0.05$ in all cases).

The HRQOL scores did not vary regarding attendance at hospital school after controlling for the mode of dialysis $(F=1.109 ; p=0.302)$.

\section{Discussion}

To the best of our knowledge, this study is the first to report on the HRQOL of children and adolescents with ESRD in sub-Saharan Africa. The number of RRT procedures which are carried out in South Africa (SA) are much more than in other parts of sub-Saharan Africa, and the findings from this study may be applicable to other regions as well. ${ }^{[18]}$ The only other study carried out in SA was done on adults. ${ }^{[19]}$

The present study found low mean HRQOL scores among children with ESRD receiving dialysis. This is similar to findings of several other authors. ${ }^{[8,9,12-15]}$ The overall mean HRQOL scores were found to be significantly lower in all patients in our cohort compared withpopulation sample mean HRQOL scores of healthy controls. ${ }^{[17]}$ This compares to the report by Goldstein et al. ${ }^{[9]}$ Moreover, Buyan et al. ${ }^{[14]}$ also reported significantly higher HRQOL scores in healthy controls in almost all domains tested compared with children with chronic kidney disease which included children on either HD or PD and children who had received a kidney transplant. The Buyan et al. ${ }^{[20]}$ study, however, utilised the KINDL scoring system and reported no significant differences between the scores in the HD and PD groups. ${ }^{[14]}$ Our finding of lower HRQOL scores in children with ESRD was not surprising as it has been reported that even children with only mild to moderate stages of CKD already have significantly lower HRQOL scores than their healthy counterparts. Children with ESRD are more often than not unable to participate in usual activities with their peers because of the very nature of the disease, which affects physical, emotional and psychosocial aspects of life. 
Table 3. Mean HRQOL Scores for children and parent proxies for different modes of dialysis

\begin{tabular}{|c|c|c|c|c|c|c|c|c|c|c|c|c|}
\hline \multirow[b]{2}{*}{$\begin{array}{l}\text { PedsQL ESRD } \\
\text { Domains }\end{array}$} & \multicolumn{6}{|c|}{ Child scores, mean (SD) } & \multicolumn{6}{|c|}{ Parent proxy scores, mean (SD) } \\
\hline & $\begin{array}{l}\text { HD } \\
(n=14)\end{array}$ & $\begin{array}{l}\text { APD } \\
(n=8)\end{array}$ & $\begin{array}{l}\text { CAPD } \\
(n=5)\end{array}$ & $\begin{array}{l}\text { Total } \\
(N=27)\end{array}$ & $F^{*}$ & $p$-value & $\begin{array}{l}\text { HD } \\
(n=13)\end{array}$ & $\begin{array}{l}\text { APD } \\
(n=8)\end{array}$ & $\begin{array}{l}\text { CAPD } \\
(n=5)\end{array}$ & $\begin{array}{l}\text { Total } \\
(n=26)\end{array}$ & $F$ & $p$-value \\
\hline General fatigue & $\begin{array}{l}60.3 \\
(12.9)\end{array}$ & $\begin{array}{l}63.3 \\
(22.8)\end{array}$ & $\begin{array}{l}90.0 \\
(16.3)\end{array}$ & $\begin{array}{l}66.7 \\
(19.8)\end{array}$ & 5.9 & 0.01 & $\begin{array}{l}59.6 \\
(22.8)\end{array}$ & $\begin{array}{l}62.5 \\
(21.1)\end{array}$ & $\begin{array}{l}80.0 \\
(14.2)\end{array}$ & $\begin{array}{l}64.4 \\
(21.6)\end{array}$ & 1.5 & 0.24 \\
\hline $\begin{array}{l}\text { About my kidney } \\
\text { disease }\end{array}$ & $\begin{array}{l}56.4 \\
(13.9)\end{array}$ & $\begin{array}{l}71.2 \\
(18.3)\end{array}$ & $\begin{array}{l}71.0 \\
(24.6)\end{array}$ & $\begin{array}{l}63.5 \\
(18.3)\end{array}$ & 2.4 & 0.11 & $\begin{array}{l}59.2 \\
(22.9)\end{array}$ & $\begin{array}{l}56.2 \\
(11.9)\end{array}$ & $\begin{array}{l}75.0 \\
(26.0)\end{array}$ & $\begin{array}{l}61.3 \\
(21.1)\end{array}$ & 1.3 & 0.30 \\
\hline Treatment problems & $\begin{array}{l}57.1 \\
(13.6)\end{array}$ & $\begin{array}{l}62.5 \\
(22.2)\end{array}$ & $\begin{array}{l}77.5 \\
(20.5)\end{array}$ & $\begin{array}{l}62.5 \\
(18.7)\end{array}$ & 2.4 & 0.11 & $\begin{array}{l}66.3 \\
(16.4)\end{array}$ & $\begin{array}{l}58.6 \\
(25.0)\end{array}$ & $\begin{array}{l}80.0 \\
(18.9)\end{array}$ & $\begin{array}{l}66.6 \\
(20.4)\end{array}$ & 1.8 & 0.19 \\
\hline $\begin{array}{l}\text { Family and peer } \\
\text { interaction }\end{array}$ & $\begin{array}{l}48.2 \\
(16.7)\end{array}$ & $\begin{array}{l}51.0 \\
(26.5)\end{array}$ & $\begin{array}{l}53.3 \\
(38.0)\end{array}$ & $\begin{array}{l}50.0 \\
(23.6)\end{array}$ & 0.1 & 0.91 & $\begin{array}{l}46.1 \\
(35.9)\end{array}$ & $\begin{array}{l}61.4 \\
(20.4)\end{array}$ & $\begin{array}{l}60.0 \\
(43.5)\end{array}$ & $\begin{array}{l}53.5 \\
(33.1)\end{array}$ & 0.4 & 0.66 \\
\hline Worry & $\begin{array}{l}52.3 \\
(18.9)\end{array}$ & $\begin{array}{l}49.1 \\
(22.4)\end{array}$ & $\begin{array}{l}49.0 \\
(8.4)\end{array}$ & $\begin{array}{l}50.7 \\
(18.1)\end{array}$ & 0.1 & 0.90 & $\begin{array}{l}54.8 \\
(25.5)\end{array}$ & $\begin{array}{l}51.2 \\
(22.6)\end{array}$ & $\begin{array}{l}53.0 \\
(11.6)\end{array}$ & $\begin{array}{l}53.4 \\
(21.9)\end{array}$ & 0.1 & 0.93 \\
\hline $\begin{array}{l}\text { Perceived physical } \\
\text { appearance }\end{array}$ & $\begin{array}{l}43.4 \\
(32.7)\end{array}$ & $\begin{array}{l}52.1 \\
(22.2)\end{array}$ & $\begin{array}{l}70.0 \\
(27.4)\end{array}$ & $\begin{array}{l}50.9 \\
(19.4)\end{array}$ & 1.5 & 0.24 & $\begin{array}{l}48.7 \\
(29.6)\end{array}$ & $\begin{array}{l}51.0 \\
(18.6)\end{array}$ & $\begin{array}{l}63.3 \\
(21.7)\end{array}$ & $\begin{array}{l}52.2 \\
(25.0)\end{array}$ & 0.7 & 0.51 \\
\hline Communication & $\begin{array}{l}62.1 \\
(19.5)\end{array}$ & $\begin{array}{l}61.2 \\
(18.7)\end{array}$ & $\begin{array}{l}79.0 \\
(17.5)\end{array}$ & $\begin{array}{l}65.0 \\
(19.4)\end{array}$ & 1.7 & 0.21 & $\begin{array}{l}70.8 \\
(29.0)\end{array}$ & $\begin{array}{l}76.2 \\
(24.9)\end{array}$ & $\begin{array}{l}86.0 \\
(16.7)\end{array}$ & $\begin{array}{l}75.4 \\
(25.6)\end{array}$ & 0.7 & 0.51 \\
\hline Total & $\begin{array}{l}54.7 \\
(9.7)\end{array}$ & $\begin{array}{l}57.8 \\
(15.3)\end{array}$ & $\begin{array}{l}67.0 \\
(10.4)\end{array}$ & $\begin{array}{l}57.9 \\
(12.1)\end{array}$ & 2.0 & 0.15 & $\begin{array}{l}58.4 \\
(18.6)\end{array}$ & $\begin{array}{l}58.7 \\
(9.9)\end{array}$ & $\begin{array}{l}69.0 \\
(12.7)\end{array}$ & $\begin{array}{l}60.5 \\
(15.4)\end{array}$ & 0.8 & 0.44 \\
\hline
\end{tabular}

Table 4. Mean differences in HRQOL scores between parent proxies and children with ESRD

\begin{tabular}{|c|c|c|c|}
\hline PedsQL ESRD domain & $\begin{array}{l}\text { Mean (SD) difference between } \\
\text { parent proxies and children's } \\
\text { reports }\end{array}$ & $t$-statistic & $p$-value \\
\hline General fatigue & $-2.3(21.3)$ & -0.527 & 0.603 \\
\hline About my kidney disease & $-2.6(24.2)$ & -0.538 & 0.595 \\
\hline Treatment problems & $3.0(23.7)$ & 0.634 & 0.532 \\
\hline Family and peer interaction & $5.0(30.7)$ & 0.814 & 0.424 \\
\hline Worry & $2.7(23.5)$ & 0.574 & 0.571 \\
\hline Perceived physical appearance & $1.3(26.3)$ & 0.253 & 0.802 \\
\hline Communication & $10.2(22.1)$ & 2.312 & 0.030 \\
\hline Total & $2.56(15.0)$ & 0.852 & 0.403 \\
\hline
\end{tabular}

Our study also found that, although not achieving statistical significance, the mean HRQOL scores were higher for children who were on PD when compared with those on HD. Goldstein et al. ${ }^{[9]}$ McKenna et al. ${ }^{[12]}$ and Kilis-Pstrusinska et al. ${ }^{[15]}$ who also used the PedsQL instrument, did not find any significant difference in HRQOL scores between children on HD and those on PD. Buyan et al. ${ }^{[14]}$ also had the same findings although they used the KINDL instrument in their study. The study on adults carried out in Cape Town in South Africa had similar findings, although a different instrument, the KDQOL-SF, was used. ${ }^{[19]}$ In the study by Kilis-Pstrusinska et al. ${ }^{[15]}$ a large multicentre study carried out on Polish children with CKD, using the PedsQL instrument found that the HRQOL was significantly higher with the use of PD compared with HD. Juergensen et al., ${ }^{[21]}$ in a study of adults with ESRD in the USA, reported that patients on PD reported a significantly higher satisfaction compared to those on HD. However, their study used a questionnaire developed solely for the purpose of their study. The use of various instruments or assessment measures makes it difficult to make direct comparisons between different renal replacement modalities. This has been alluded to by McKenna et al. ${ }^{[12]}$ and Lai. ${ }^{[22]}$

In analysing HRQOL scores for children on PD, it was found that children who were on CAPD reported higher scores than those on APD. This was an unexpected finding as we had assumed that the use of APD would make the dialysis procedure less cumbersome for the patients and caregivers, with less interference in the patients' lives and thus would be preferred. Possible reasons for the apparent preference for CAPD v.s APD may be the flexibility of CAPD compared with APD and the possibly negative psychological effect of having to be attached to the APD machine for long hours at a time.

Our study did not find any significant influence of age, gender, mode of dialysis, duration of dialysis, number of medications, hospitalisations and routine clinic visits or attendance at the hospital school on the reported HRQOL scores by both children and their caregivers. This finding is similar to reports by Gerson et al. ${ }^{[20]}$ and Amr et al. ${ }^{[23]}$ Surprisingly, although the children with significant non-renal comorbidities had lower HRQOL scores, the presence or absence of a non-renal comorbidity did not appear to have a significant impact on the HRQOL scores.

It has been reported that youths who have had CKD for a long period of time had better HRQOL scores in the physical and emotional functioning domains. ${ }^{[20]}$ The explanation for this could be that the children and their caregivers learn to adapt to having multiple comorbidities and are able to handle such situations better. 
The present study found higher reported mean HRQOL scores from the parent proxies when compared with those of the children on dialysis treatment, although this was not of statistical significance. Several studies have reported varying HRQOL scores between parent-proxies and patients. ${ }^{[9,12-15,20,24]}$ The differences reported in these studies were generally not statistically significant but Buyan et al. ${ }^{[14]}$ Gerson et al. ${ }^{[20]}$ and Chiu et al. ${ }^{[24]}$ found that parents reported mean HRQOL scores that were higher than those reported by their children, while Goldstein et al. ${ }^{[9]}$ McKenna et al. ${ }^{[12]}$ Neul et al. ${ }^{[13]}$ and Kilis-Pstrusinska et al. ${ }^{[15]}$ reported the opposite, with the children's scores being higher than those reported by their parent-proxies. Only the study by Buyan et al. ${ }^{[14]}$ reported significant differences for almost all the domains tested. Kilis-Pstrusinska et al. ${ }^{[15]}$ found the difference to be significant for children who were on PD but not so with children on HD. These highly varied findings appear to imply that parents do not really understand the effects of ESRD and its treatment modality on the general health of their children, as their perceptions either overestimate or underestimate those of their children. It is therefore important to obtain reports from both the children and their parent proxies so that management and counseling can be better tailored to the specific needs of each family.

\section{Conclusion}

Children with ESRD receiving dialysis have low HRQOL scores. Those on PD reported better HRQOL than those on HD, which implies that children on HD may require even more special support. Furthermore, parent proxies reported higher scores than those reported by the children. This raises concern about the extent of care and support being given to the children on either modality of RRT, as well as parental motivation. The importance of assessing the HRQOL of children with chronic conditions such as ESRD, with the aim of offering them care which is as holistic as possible, cannot be overemphasised.

Acknowledgements. The authors are thankful to the patients and their caregivers for their participation in the study. The authors also wish to acknowledge the International Society of Nephrology and the International Paediatric Nephrology Association for sponsoring the corresponding author (PNO) in paediatric nephrology subspecialty training at Charlotte Maxeke Johannesburg Academic Hospital, Johannesburg, South Africa. Author contributions. Study conception and design: PNO, CL. Data collection: PNO, BS, TK. Data analysis and interpretation: PNO, TK, GM, CL. Conceptualising and writing the manuscript: PNO. Technical review of manuscript: PNO, BS, TK, GM, CL. Approval of final manuscript: PNO, BS, TK, GM, CL.

Funding. None.

Conflict of interest. None.

1. Copelovitch L, Warady BA, Furth SL. Insights from the chronic kidney disease in children (CKiD) study. Clin J Am Soc Nephrol 2011;6(8):2047-2053. https:// doi.org/10.2215/cjn.10751210.

2. Bruce MA, Beech BM, Sims M, et al. Social environmental stressors, psychological factors, and kidney disease. J Investig Med 2009;57(4):583-589. https://doi.org/10.231/jim.0b013e31819dbb91.

3. Kaptein AA, van Dijk S, Broadbent E, Falzon L, Thong M, Dekker FW. Behavioural research in patients with end-stage renal disease: A review and research agenda. Patient Educ Couns 2010;81(1):23-29. https://doi. org/10.1016/j.pec.2009.10.031.
4. The World Health Organization Quality of Life assessment (WHOQOL): Position paper from the World Health Organization. Soc Sci Med 1995;41(10):1403-1409. https://doi.org/10.1016/0277-9536(95)00112-k

5. Eser E, Yuksel H, Baydur H, et al. The psychometric properties of the new Turkish generic health-related quality of life questionnaire for children (Kid-KINDL). Turk Psikiyatri Derg 2008;19(4):409-417.

6. Hays RD, Kallich JD, Mapes DL, Coons SJ, Amin N, Carter WB. Kidney disease quality of life short form (KDQOL-SF), version 1.3: A manual for use and scoring. http://www.rand.org/content/dam/rand/pubs/papers/2006/P7994.pdf (accessed 13 June 2016)

7. Varni JW, Seid M, Kurtin PS. PedsQL 4.0: Reliability and validity of the Pediatric Quality of Life Inventory version 4.0 generic core scales in healthy and patient populations. Med Care 2001;39(8):800-812. https://doi.org/10.1097/00005650200108000-00006

8. Goldstein SL, Graham N, Warady BA, et al. Measuring health-related quality of life in children with ESRD: Performance of the generic and ESRD-specific instrument of the Pediatric Quality of Life Inventory (Peds QL). Am J Kidney Dis 2008;51(2):285-297. https://doi.org/10.1053/j.ajkd.2007.09.021

9. Goldstein SL, Graham N, Burwinkle T, Warady B, Farrah R, Varni JW Health-related quality of life in pediatric patients with ESRD. Pediatr Nephrol 2006;21(6):846-850. https://doi.org/10.1007/s00467-006-0081-y

10. Eijsermans RM, Creemers DG, Helders PJ, Schroder CH. Motor performance, exercise tolerance, and health-related quality of life in children on dialysis. Pediatr Nephrol 2004;19(11):1262-1266. https://doi.org/10.1007/s00467-004-1583-0.

11. Gerson AC, Riley A, Fivush BA, et al. Assessing health status and health care utilisation in adolescents with chronic kidney disease. J Am Soc Nephrol 2005;16(5):1427-1432. https://doi.org/10.1681/asn.2004040258

12. McKenna AM, Keating LE, Vigneux A, Stevens S, Williams A, Geary DF. Quality of life in children with chronic kidney disease - patient and caregiver assessments. Nephrol Dial Transplant 2006;21(7):1899-1905. https://doi.org/10.1093/ndt/ qfl091

13. Neul SK, Minard CG, Currier H, Goldstein SL. Health-related quality of life functioning over a 2 -year period in children with end-stage renal disease. Pediatr Nephrol 2013;28(2):285-293. https://doi.org/10.1007/s00467-012-2313-7.

14. Buyan N, Turkmen MA, Bilge I, et al. Quality of life in children with chronic kidney disease (with child and parent assessments). Pediatr Nephrol 2010;25(8):14871496. https://doi.org/10.1007/s00467-010-1486-1

15. Kilis-Pstrusinska K, Medynska A, Chmielewska IB, et al. Perception of health-related quality of life in children with chronic kidney disease by the patients and their caregivers: Multicenter national study results. Qual Life Res 2013;22(10):2889-2897. https://doi.org/10.1007/s11136-013-0416-7

16. Varni JW, Limbers CA, Burwinkle TM. Impaired health-related quality of life in children and adolescents with chronic conditions: A comparative analysis of 10 disease clusters and 33 disease categories/severities utilizing the PedsQL 4.0 Generic Core Scales. Health Qual Life Outcomes 2007;5:43. https://doi. org/10.1186/1477-7525-5-43

17. Varni JW, Burwinkle TM, Seid M, Skarr D. The PedsQL 4.0 as a pediatric population health measure: Feasibility, reliability and validity. Ambul Pediatr 2003;3(6):329-341. https://doi.org/10.1367/1539-4409(2003)003<0329:tpaapp >2 .0.co;2 PMID: 14616041

18. Naicker S. End-stage renal disease in sub-Saharan and South Africa. Kidney Int Suppl 2003;83:S119-S122. https://doi.org/10.1046/j.1523-1755.63.s83.25.x

19. Okpechi IG, Nthite T, Swanepoel CR. Health-related quality of life in patients on hemodialysis and peritoneal dialysis. Saudi J Kidney Dis Transpl 2013;24(3):519526. https://doi.org/10.4103/1319-2442.111036

20. Gerson AC, Wentz MA, Abraham AG, et al. Health-related quality of life of children with mild to moderate chronic kidney disease. Pediatrics 2010;125(2):e349-e357. https://doi.org/10.1542/peds.2009-0085

21. Juergensen E, Wuerth D, Finkelstein SH, Juergensen PH, Bekui A, Finkelstein FO. Hemodialysis and peritoneal dialysis: Patients' assessment of their satisfaction with therapy and the impact of the therapy on their lives. Clin J Am Soc Nephrol 2006;1(6):1191-1196. https://doi.org/10.2215/cjn.01220406

22. Lai WM. Quality of life in children with end-stage renal disease: Does treatment modality matter? Perit Dial Int 2009;29(Suppl 2):S190-S191.

23. Amr M, Bakr A, El Gilany AH, Hammad A, El-Refaey A, El-Mougy A. Multimethod assessment of behavior adjustment in children with chronic kidney disease. Pediatr Nephrol 2009;24(2):341-347. https://doi.org/10.1007/s00467008-1012-x.

24. Chiu MC, Ng CF, Lee LP, Lai WM, Lau SC. Automated peritoneal dialysis in children and adolescents - benefits: A survey of patients and parents on healthrelated quality of life. Perit Dial Int 2007;27(Suppl 2):S138-S142.

Accepted 22 November 2017. 